\title{
Surface Area, Crystal Morphology and Characterization of Transition Alumina Powders from a New Gibbsite Precursor
}

\author{
Antonio Carlos Vieira Coelho ${ }^{\text {a*, Helena de Souza Santos }}{ }^{\mathrm{b}}$, Pedro Kuniiko Kiyohara ${ }^{\mathrm{b}}$, \\ Kelly Nanci Pinto Marcos ${ }^{\mathrm{a}}$, Pérsio de Souza Santos ${ }^{\mathrm{a}}$ \\ ${ }^{a}$ Laboratório de Matérias-Primas Particuladas e Sólidos Não Metálicos, \\ Departamento de Engenharia Metalúrgica e de Materiais, Escola Politécnica, \\ Universidade de São Paulo - USP, Av. Prof. Luciano Gualberto, travessa 3, 380, \\ 05508-970 São Paulo - SP, Brazil \\ ${ }^{\mathrm{b}}$ Laboratório de Microscopia Eletrônica - LME, Departamento de Física Geral, \\ Instituto de Física - IF, Universidade de São Paulo - USP, CP 66318, 05315-970
}

Received: February 23, 2007; Revised: June 13, 2007

\begin{abstract}
A new procedure was used to prepare a microcrystalline powder constituted by thin euhedral hexagonal gibbsite plates, 0.2 to $0.6 \mu \mathrm{m}$ in diameter and $32 \mathrm{~nm}$ thick. The powder, fired between 200 and $1000{ }^{\circ} \mathrm{C}$, produced chi and kappa transition aluminas. Alpha-alumina is formed from $1000{ }^{\circ} \mathrm{C}$ and recrystallized up to $1500{ }^{\circ} \mathrm{C}$. At $1000{ }^{\circ} \mathrm{C}$, kappa- and alpha-alumina coexisted, but kappa-alumina could only be characterized by SAED. The details of the internal organization of the transition alumina pseudomorphs were clearly observable in TEM due to the great thinness of the I-gibbsite plates. The specific surface area varied from pristine I-gibbsite $\left(24.9 \mathrm{~m}^{2} . \mathrm{g}^{-}\right.$ $\left.{ }^{1}\right)$ to chi- and kappa transition aluminas $\left(25.4 \mathrm{~m}^{2} \cdot \mathrm{g}^{-1}\right)$ at $1000{ }^{\circ} \mathrm{C}$ to alpha-alumina $\left(4.0 \mathrm{~m}^{2} \cdot \mathrm{g}^{-1}\right)$ at $1500{ }^{\circ} \mathrm{C}$. The maximum value of specific surface area is $347 \mathrm{~m}^{2} \cdot \mathrm{g}^{-1}$ in chi-alumina powder at $300{ }^{\circ} \mathrm{C}$, a difference from Bayer gibbsite, in which the chi-alumina highest surface area is $370 \mathrm{~m}^{2} \cdot \mathrm{g}^{-1}$ at $400{ }^{\circ} \mathrm{C}$.
\end{abstract}

Keywords: gibbsite, transition aluminas, active aluminas, alpha-alumina

\section{Introduction}

Synthetic gibbsite is the most important alumina chemical, either as an aluminum trihydroxide or as precursor for alumina powders for advanced and traditional ceramics, catalysts and catalyst carriers, adsorbents, aluminum, paper, rubber, plastics and other chemical process industries. A great industrial value of gibbsite is due to fact that it is the only aluminum hydroxide that, by thermal processing, is able to produce all transition aluminas (from the chi and gamma series) and alpha-alumina.

Usually, gibbsite, natural or synthetic crystals, are of micrometric size; their structure is triclinic, but common shapes are tabular with pseudohexagonal profiles and prisms of hexagonal basis ${ }^{1,2}$. By transmission electron microscopy (TEM), many of the prisms appear as rectangles if they stand sideways on the TEM support.

McBride et al. ${ }^{3}$ presented TEM of hexagonal platy microcrystals of gibbsite prepared by Gastuche and Herbillon`s procedure ${ }^{4}$ of aging of gelatinous amorphous aluminum hydroxide precipitate in water, at $\mathrm{pH}$ 4.6, for one month at room temperature; the aluminum hydroxide was prepared by the reaction between aluminum chloride and sodium hydroxide solutions. $\mathrm{Hsu}^{5}$, reviewing the literature on aluminum hydroxides, reproduced TEM of hexagonal plates of microcrystals of gibbsite, from the aging of aluminum hydroxide, in water containing sodium and perchlorate ions, at room temperature ${ }^{6}$.

McZura et al. $^{7}$ and Misra ${ }^{8}$ described, by TEM, very uniforms hexagonal platy microcrystals, about $1 \mu \mathrm{m}$ in diameter, produced by a patented process from an "organic-free aluminate liquor" for use as coating pigment for paper", in ALCOA Hydral Series. Sweegers et al. ${ }^{10}$ reviewed the morphology of gibbsite crystals grown from pure and impure aqueous sodium aluminate solutions and Adamo et al. ${ }^{11}$ in tartrate solutions.
Pseudohexagonal platty gibbsite microcrystals are normal components of Brazilian bauxites ${ }^{12}$ and high alumina gibbsite clays ${ }^{13,14}$.

Brown et al. ${ }^{15}$ were the first to demonstrate that the thermal decomposition of gibbsite crystals may follow dual transformations at normal pressure; the first leads to the chi-alumina series and the second to the boehmite $(\mathrm{AlOOH})$ or gamma series. Both transformations are pseudomorphic and topotactic in relation to gibbsite axis ${ }^{16}$. Both series produce several alumina structures, the so-called transition aluminas and both end, at $1100{ }^{\circ} \mathrm{C}$, in alpha-alumina. In consequence, the great value of gibbsite is because it is the only of all aluminum hydroxides that may produce all transition aluminas. This property makes synthetic gibbsite the most important alumina chemical, either as a crystalline aluminum hydroxide or as an alumina precursor. The so-called Bayer gibbsite is produced as an intermediate in Bayer process for aluminum production ${ }^{8}$. It is used as a precursor for production of alumina powders for several chemical processes. So, the thermal transformation of gibbsite in the two series was extensively studied, specially the development of high surface areas, pore structures and texture of the transition aluminas. Wefers and Bell ${ }^{17}$; Wefers and Misra ${ }^{18}$ reviewed and summarized the most important results from these studies. Wefers ${ }^{19}$ reviewed the industrial and laboratorial processes for producing crystalline gibbsite.

Bayer gibbsite particles, as in ALCOA C-30, when examined by scanning electron microscopy (SEM), are roughly spherical agglomerates of tabular and prismatic single crystals; the agglomerates diameter vary between 40 and $200 \mu \mathrm{m}$; each crystal, tabular or prismatic, has a diameter between 5 and $10 \mu \mathrm{m}^{7,8}$. The majority of the thermal decomposition studies of gibbsite has been conducted on Bayer crystal agglomerates. 
Wefers and Misra ${ }^{18}$ presented TEM data on the texture of the crystals of the chi-alumina series; the micrographs are from chiand kappa-alumina pseudomorphs from prismatic or acicular single crystals of Bayer gibbsite, observed sideways: the original gibbsite crystal appears as rectangular and the transformation into chi-alumina is described as an exfoliation of lamellae. Suzuki ${ }^{20}$ and later Wefers and Bell ${ }^{17}$, published micrographs of thin hexagonal platy chi-alumina pseudomorphs observed parallel to the c-axis: the texture of the hexagonal plate is described as a "network of submicroscopic cracks and devices in the heated crystal", this texture, later, has been described as "sponge-like" or as being constituted by "jigsaw" particles.

Pandolfelli et al..$^{21}$ described the alterations by calcination of the physical, morphological and rheological properties of ALCOA C-30 Bayer gibbsite.

The aluminum hydroxides which crystallizes in water in which no substance is dissolved is the trihydroxide bayerite; if $\mathrm{Na}^{+}$or $\mathrm{K}^{+}$ions are present, gibbsite is formed ${ }^{22}$. Amalgamated aluminum reacts with water producing amorphous aluminum hydroxide which crystallizes in bayerite; if linear alcohols are added several aluminum hydroxides may crystallize, depending on the alcohol ${ }^{23}$.

Recently, Souza Santos et al. ${ }^{24}$ studied the reaction between aluminum powder and water, using iodine as an "activator" 25 in place of mercury. Euhedral, very thin, regular hexagonal plates were formed in the narrow temperature range of $50-60{ }^{\circ} \mathrm{C}$, having 0.2 to $0.6 \mu \mathrm{m}$ diameter by TEM; a few crystals may have diameters in the nanometric range (6-7 nm). The smaller size and thinness of these gibbsite hexagonal platelets could allow a detailed study by TEM of the variation with of the pseudomorphs texture increasing temperature in the series: gibbsite $\rightarrow$ chi-alumina $\rightarrow$ kappa-alumina $\rightarrow$ alpha-alumina.

The purpose of this paper is to characterize the differences from Bayer gibbsite crystals which are observed in the specific surface area, internal structure and morphology of the microcrystals of the transition aluminas of the chi-alumina series formed from the gibbsite crystals by the new method after heated between 200 and $1500{ }^{\circ} \mathrm{C}$, aiming to obtain aluminas with new or improved properties.

\section{Materials and Methods}

\subsection{Gibbsite preparation by the "iodine method" 24}

ALCOA 123 uncoated Al-powder was used (100\% minus $n^{\circ} 325$ ABNT sieve; Al-99.7\%; Si-O-0.15\%; Fe-0.17\%). In a round botton two liters three necked Pyrex flask, in the following sequence were placed: $500 \mathrm{~mL}$ of water; $27.0 \mathrm{~g}$ of Al powder and $50 \mathrm{~mL}$ of an iodine solution ( $5.0 \mathrm{~g}$ of iodine crystals dissolved in $50 \mathrm{~mL} 95 \%$ ethanol). The system was stirred one hour for homogenization and heated to $60 \pm 1{ }^{\circ} \mathrm{C}$ by thermostat controlled heating mantle; a water cooled condenser was fitted to the flask. It took a minimum of two weeks for the aluminum react completely. The condenser was taken out in the last four hours to assure that if any remaining iodine was eliminated. The white dispersion presented strong dityndallism by stirring, an indication of anisodiametric shape of the particles. The white dispersion is centrifuged in polyethylene tubes in a Servall centrifuge at $3500 \mathrm{rpm}$ for 30 minutes. The white precipitate was washed four times with its original volume of $95 \%$ ethanol. The white precipitate of aluminum hydroxide gibbsite (called "I-gibbsite" in this paper) was dried at $60^{\circ} \mathrm{C}$ for 24 hours and the white powder was ready for characterization and other tests; the yield in $\mathrm{Al}(\mathrm{OH})_{3}$ was $86-87 \%$, based in the equation:

$$
\mathrm{Al}+3 \mathrm{H}_{2} \mathrm{O} \rightarrow \mathrm{Al}(\mathrm{OH})_{3}+1.5 \mathrm{H}_{2}
$$

\subsection{Thermal treatment}

Three to four grams of the unpressed dry white powder were program fired on a platinum foil in an electric furnace EDG, São
Carlos, SP, for 3 hours at the maximum temperature, from $200{ }^{\circ} \mathrm{C}$ up to $1500^{\circ} \mathrm{C}$, with $100{ }^{\circ} \mathrm{C}$ intervals; natural cooling was used. After cooling, the fired powder was characterized by $\mathrm{X}$ ray diffraction, transmission electron microscopy, selected area electron diffraction (SAED), elemental microanalysis and for measurement of the specific surface area.

\subsection{Methods}

The Differential Thermal Analysis (DTA) was conducted in an equipment by B.P. Engenharia, Campinas, SP, Brazil, up to $1100{ }^{\circ} \mathrm{C}$ in open air.

The $\mathrm{X}$ ray diffraction (XRD) was conducted in a Philips X-pert MPD model equipment, operating at $40 \mathrm{kV}$ and $40 \mathrm{~mA}$, between $1^{\circ}$

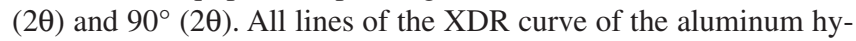
droxide powder prepared at $60{ }^{\circ} \mathrm{C}$ correspond to gibbsite lines listed in ICDD file $\mathrm{n}^{\circ} 7-324$ and ref. ${ }^{18}$; the more intense line is the $4.85 \AA$ gibbsite reflection. No other Al-hydroxide is detected. The transition aluminas were characterized from ICDD files and ref. ${ }^{18}$.

The dried powder was dispersed in distilled water and prepared in the conventional manner for transmission electron microscopy (TEM). A Philips CM-200 equipment, operating at $200 \mathrm{kV}$ was used. The same microscope was used as a diffraction camera to characterize the crystalline alumina phases structures by SAED and for elemental microanalysis by electron diffraction spectroscopy (EDS).

The specific surface area (in $\mathrm{m}^{2} \cdot \mathrm{g}^{-1}$ ) of the fired powders was measured by the BET-nitrogen adsorption method using a Micromeritics ASAP 2010 model. The adsorption data were taken using 99.999\% pure nitrogen gas (Air Liquid), at the liquid nitrogen temperature $(77 \mathrm{~K})$. The experimental data were taken in the $0.01-0.30$ range of partial pressures.

\section{Results and Discussion}

\subsection{Gibbsite characterization}

Figure 1 is a transmission electron micrograph of some wellformed gibbsite platy crystals. Their diameters are in the $0.2 \mu \mathrm{m}$ to $0.6 \mu \mathrm{m}$ interval. They have hexagonal profiles, various thickness, the

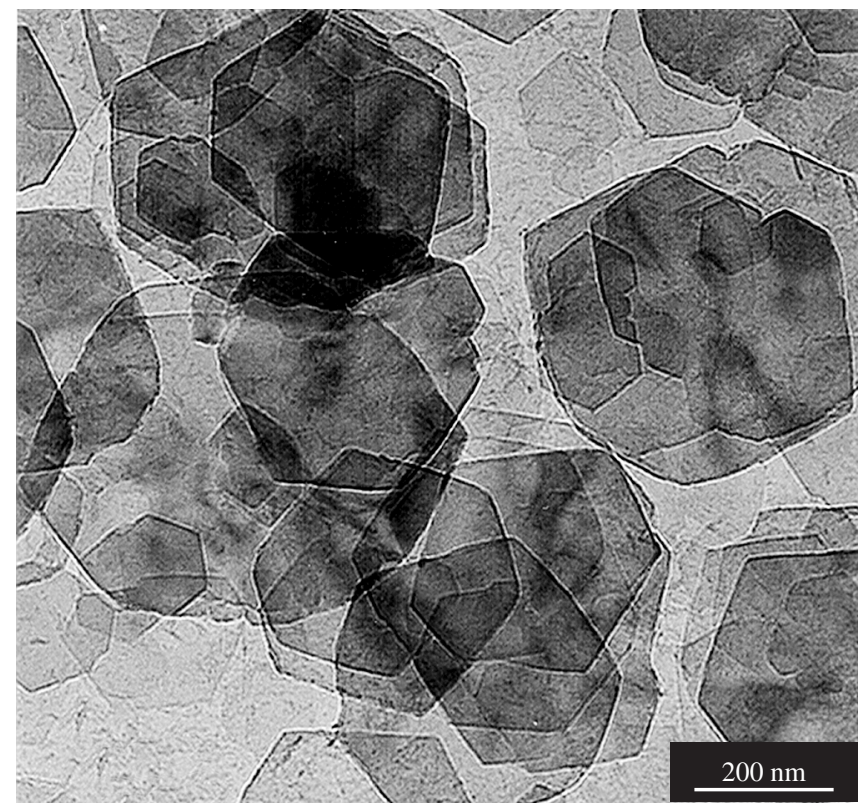

Figure 1. Transmission electron micrograph of some well-formed I-gibbsite platy crystals (LME-IF-USP). 
majority being very thin. The SAED confirms the gibbsite structure characterized by the XRD curve of Figure 2. EDS elemental microanalysis indicates the absence of iodine in the microcrystals that were examined. The hexagonal platy crystals are similar to those used for paper coating ${ }^{9}$ and are completely different from the Bayer gibbsite agglomerates $^{7,8}$.

The DTA curve of Figure 3a shows an intense endothermic peak starting at $250{ }^{\circ} \mathrm{C}$ and with maximum intensity at $300-320^{\circ} \mathrm{C}$. No endothermic peak is observed at $525-550^{\circ} \mathrm{C}$, an indication of absence of boehmite, either as an impurity or formed by partial dehydroxilation. The endothermic peak corresponds to the complete dehydroxilation of the gibbsite crystal, according to the equation:

$$
2 \mathrm{Al}(\mathrm{OH})_{3} \rightarrow \mathrm{Al}_{2} \mathrm{O}_{3}+3 \mathrm{H}_{2} \mathrm{O} \text { (vapour) }
$$

That reaction occurs when the gibbsite crystals are fine grained and there is free escape of the water vapour. In these conditions, the transition chi-alumina series is formed, starting at $273{ }^{\circ} \mathrm{C}$, according to Wefers and Misra ${ }^{18}$.

\subsection{Aluminas characterization by XRD}

Figure 4, adapted from ref. ${ }^{18}$, shows the Bayer gibbsite to the chi-alumina series transformation by increasing temperatures. The following temperature differences can be observed in the transition temperatures of the I-gibbsite microcrystals prepared by iodine activation of aluminum powders from Bayer gibbsite: a) chi-alumina starts to form at $200{ }^{\circ} \mathrm{C}\left(273{ }^{\circ} \mathrm{C}\right.$ in ref. $\left.{ }^{18}\right)$; b) chi-alumina remains up to $900{ }^{\circ} \mathrm{C}$, while $753{ }^{\circ} \mathrm{C}$ is the upper limit, according to ref. ${ }^{18}$; c) kappaalumina exists in a shorter temperature interval $\left(900\right.$ to $1000{ }^{\circ} \mathrm{C}$ ), instead of 753 to $1020^{\circ} \mathrm{C}^{18}$; and d) alpha-alumina crystallization starts at $1000{ }^{\circ} \mathrm{C}$, because its three strongest lines are observed (instead $1020{ }^{\circ} \mathrm{C}$ in ref. ${ }^{18}$ ); no kappa-alumina line is observed in the $1000{ }^{\circ} \mathrm{C}$ $\mathrm{XRD}$ curve; sintering, recrystalization and growth of the alpha-alumina microcrystals continues up to $1500{ }^{\circ} \mathrm{C}$. Figure 5 presents some XRD curves from I-gibbsite fired between 200 and $1500{ }^{\circ} \mathrm{C}$.

\subsection{Specific surface area}

The value of the specific surface area of the pristine I-gibbsite crystals is $29 \mathrm{~m}^{2} \cdot \mathrm{g}^{-1}$ (Figure 3), which is bigger than from Hydral aluminum hydroxide, having the same crystal shape (the values are 6-8 $\mathrm{m}^{2} \cdot \mathrm{g}^{-1}$ and $12 \mathrm{~m}^{2} \cdot \mathrm{g}^{-1}$ for the two types ${ }^{9}$ ). The variation of the specific surface area of the I-gibbsite powder with firing temperatures

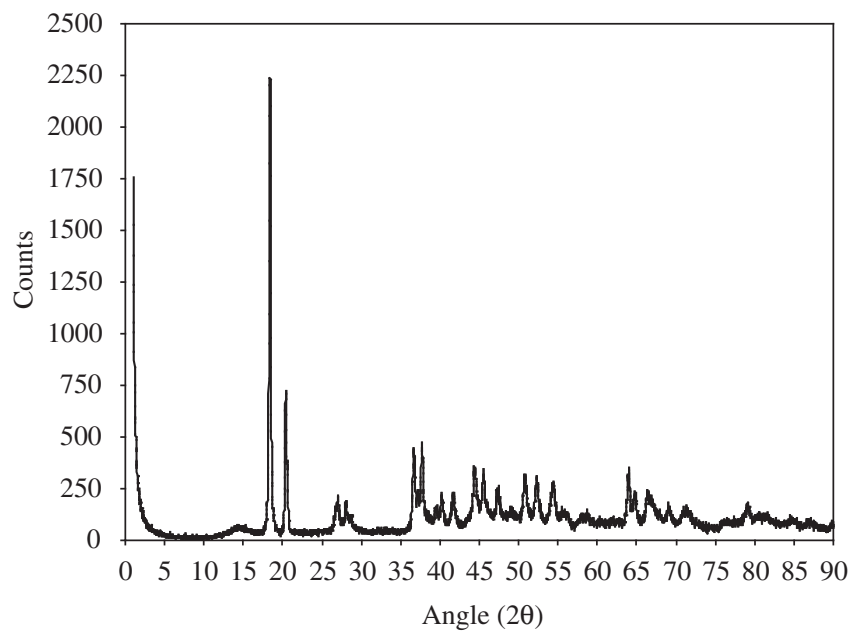

Figure 2. XRD curve of well-formed gibbsite platy crystals showed in Figure 1 , confirming the gibbsite structure. between 200 and $1500{ }^{\circ} \mathrm{C}$ is shown in Figure $3 \mathrm{~b}$ in comparison with Bayer gibbsite data from literature (Figure $3 \mathrm{c})^{18}$. It can be observed that the maximum value observed for the fired powders of I-gibbsite is obtained at $300{ }^{\circ} \mathrm{C}$, the same temperature of the endothermic dehydroxilation peak of the end of the gibbsite to chi-alumina transformation shown in the DTA curve (Figure 3a).

The maximum value is $347 \mathrm{~m}^{2} \cdot \mathrm{g}^{-1}$ from a sample fired at $300{ }^{\circ} \mathrm{C}$, which is close to the maximum value from of the gibbsite form literature - Figure $3 \mathrm{c}, 370 \mathrm{~m}^{2} \cdot \mathrm{g}^{-1}$ at $650{ }^{\circ} \mathrm{C}$. Therefore, either at $300{ }^{\circ} \mathrm{C}$ (I-gibbsite) or at $650{ }^{\circ} \mathrm{C}$ (Bayer gibbsite), both have chi-alumina structure; so, the most probable cause of the difference for achieving the temperature for producing maximum surface area is the smaller internal texture of the chi-alumina crystals from I-gibbsite. According to Oberlander ${ }^{26}$, activated aluminas having specific surface areas higher than $100 \mathrm{~m}^{2} \cdot \mathrm{g}^{-1}$, are considered "high surface area aluminas". So, high surface area alumina can be produced firing I-gibbsite in the $200-900{ }^{\circ} \mathrm{C}$ range.

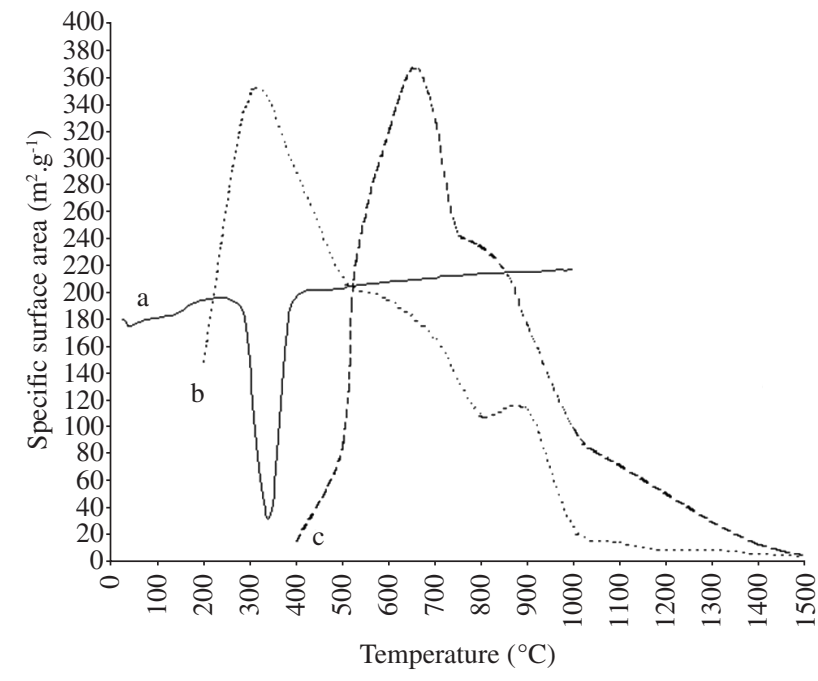

\begin{tabular}{cc}
\hline Temperature $\left({ }^{\circ} \mathrm{C}\right)$ & BET area $\left(\mathrm{m}^{2} \cdot \mathrm{g}^{-1}\right)$ \\
25 & 29.4 \\
200 & 148 \\
300 & 347 \\
400 & 289 \\
500 & 211 \\
600 & 195 \\
700 & 165 \\
800 & 110 \\
900 & 113 \\
1000 & 25.4 \\
1100 & 14.4 \\
1200 & 8.2 \\
1300 & 8.3 \\
1400 & 5.9 \\
1500 & 4.0 \\
\hline
\end{tabular}

Figure 3. a) DTA curve of I-gibbsite; b) Curve representing specific surface area data of I-gibbsite after thermal activation; c) Curve representing specific surface area data of a Bayer gibbsite after thermal activation; and d) Specific surface area (BET) data of I-gibbsite after thermal activation. 


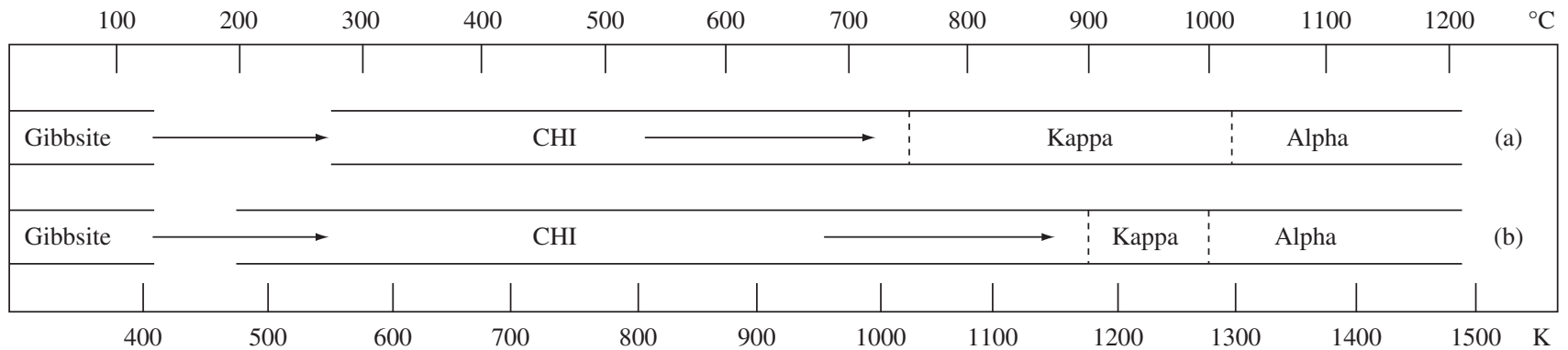

Figure 4. Thermal transformation series: a) Bayer gibbsite: gibbsite $\mathrm{Al}(\mathrm{OH})_{3} \rightarrow$ chi-alumina $\rightarrow$ kappa-alumina $\rightarrow$ alpha-alumina (adapted from ref. ${ }^{18}$ ); and b) I-gibbsite: same transformation series, but in different temperatures.

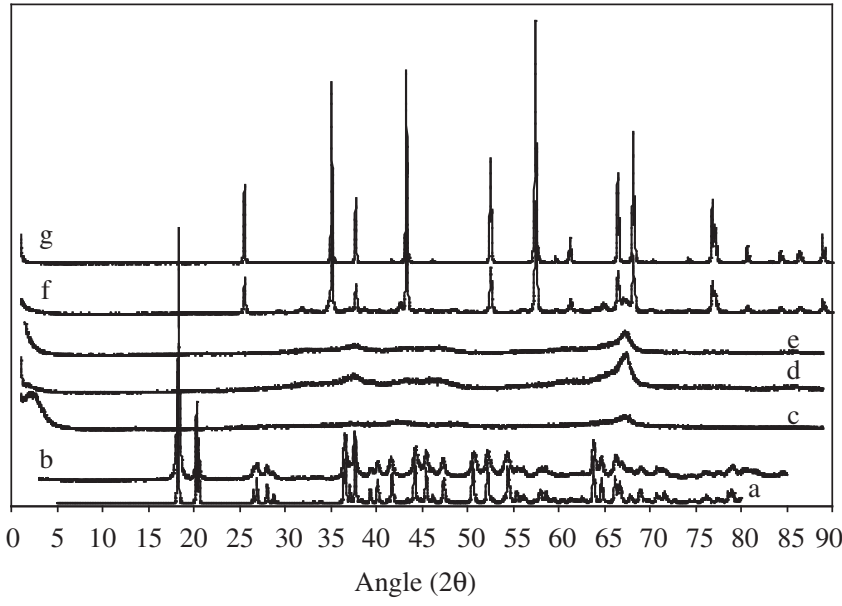

Figure 5. XRD curves from I-gibbsite fired between 300 and $1500{ }^{\circ} \mathrm{C}$ : a) Bayer gibbsite; b) pristine I-gibbsite; c) I-gibbsite fired at $300{ }^{\circ} \mathrm{C}$; d) $800{ }^{\circ} \mathrm{C}$; e) $900{ }^{\circ} \mathrm{C}$; f) $1000{ }^{\circ} \mathrm{C}$; and g) $1500{ }^{\circ} \mathrm{C}$.

\subsection{Electron microscopy and SAED}

The thickness of I-gibbsite crystal can be calculated, assuming the microcrystal as a prism of regular hexagonal basis; the gibbsite density is $2.42 \mathrm{~g} / \mathrm{cm}^{3,18}, 0.5 \mu \mathrm{m}$ diameter and specific surface area of $29.4 \mathrm{~m}^{2} \cdot \mathrm{g}^{-1}$ (Figure $3 \mathrm{~d}$ ): the calculated thickness is $32 \mathrm{~nm}$, which corresponds to 66 gibbsite $(0.485 \mathrm{~nm})$ layers.

The fired samples, after being characterized by XRD, were examined by TEM to compare the internal morphology changes of the aluminas pseudomophs with the pristine I-gibbsite hexagonal platy microcrystals of Figure 1. SAED was used to characterize the crystalline structure of single microscopical crystals.

Very early, at $200{ }^{\circ} \mathrm{C}$, but better at $300{ }^{\circ} \mathrm{C}$, SAED characterized gibbsite in many crystals, but several chi-alumina hexagonal pseudomorphs were also characterized; so, several gibbsite microcrystals had dehydroxilated into chi-alumina and the original shapes of the crystals was maintained, forming the chi-alumina pseudomorphs. Figure 6 shows $300{ }^{\circ} \mathrm{C}$ chi-alumina pseudomorphs with an internal fine granularity; the majority of the grains are chi-alumina crystals; the surface of the plates is not smooth anymore; that stage constitute the initial nucleation stage of the chi-alumina series characterized by the appearance of the granularity.

At $300{ }^{\circ} \mathrm{C}$, but better at $500 / 600{ }^{\circ} \mathrm{C}$, inside the thinnest hexagonal plates (pseudomophs), an arrangement can be observed of the granules into an hexagonal patterns, giving the appearance of a mosaic structure to the pseudomorphs. The arrangement is still visible at $700{ }^{\circ} \mathrm{C}$, but it is not easily observable in thicker plates or at higher temperatures due to the increased particle size. Each granule is a microcrystal of chi-

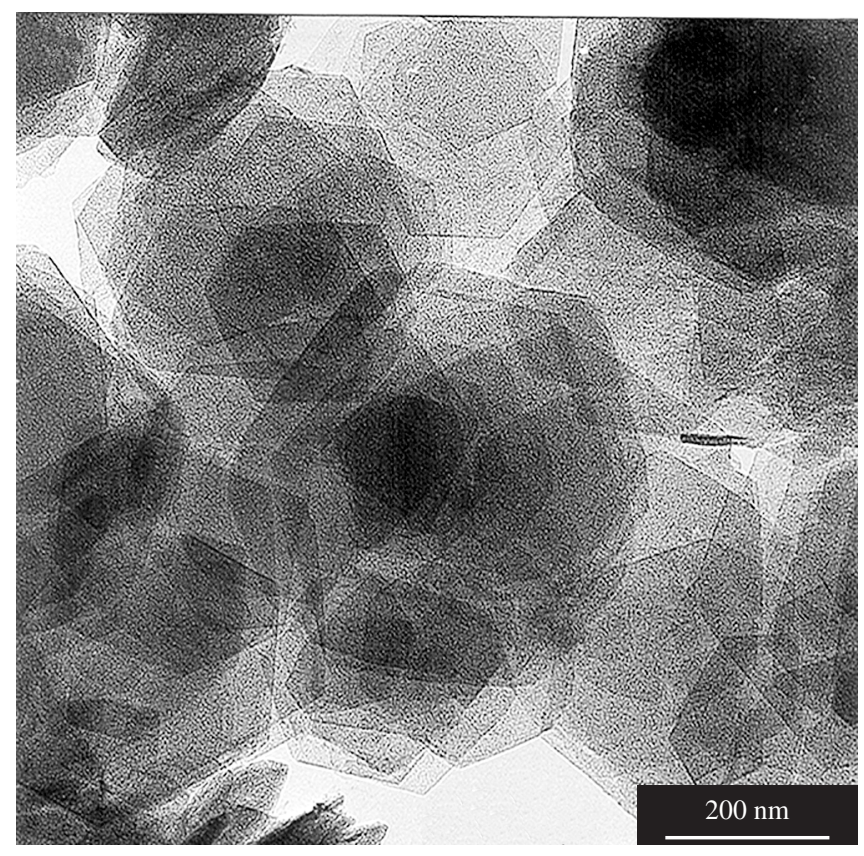

Figure 6. TEM of chi- $\mathrm{Al}_{2} \mathrm{O}_{3}$ from I-gibbsite platy crystals fired at $300{ }^{\circ} \mathrm{C}$ (LME-IF-USP).

alumina. It can be concluded that the maximum value of the specific surface area occurs at $300{ }^{\circ} \mathrm{C}$, when the chi-alumina granules inside the pseudomorphs (Figure 6) have the smallest size and the gibbsite to chi-alumina transition or reaction is complete; increasing temperature, increases the sizes of the chi-alumina nuclei and decreases the specific surface area of the transition alumina.

The earlier transmission electron micrographs of chi-alumina pseudomorphs from fired I-gibbsite hexagonal plates showed only an internal porosity and no regular arrangement of the grains; even the more recent papers by Levin and Brandon ${ }^{27}$ and by Souza Santos et $a .^{28}$ do no show that hexagonal arrangement of the chi-alumina microcrystals shown in Figure 6.

Figure 7 is a TEM of chi-alumina pseudomorphs fired at $700{ }^{\circ} \mathrm{C}$, where the increased granularity in comparison with Figure 6 can be observed. It can clearly be observed that the coarse grains have lost the round shape shown in Figure 6 and acquired a sharp platy one; from this crystal growth results sharper and more intense SAE and $\mathrm{X}$ ray reflections.

At $800^{\circ} \mathrm{C}$, it is possible to observe that many platy granules inside the pseudomorphs have acquired hexagonal profiles; XRD characterizes only chi-alumina and SAED confirms that structure for the hexagonal grains. Increasing the temperature, XRD and SAED still 
shows the chi-alumina structure. The granularity of the pseudomorphs becomes coarser with the increased temperatures.

But at $900{ }^{\circ} \mathrm{C}$, all the granules have platy hexagonal shapes and XRD and SAED confirm kappa-alumina structure for the grains. The pseudomorphs profiles have not changed. Figure 8 is a TEM of kappa-alumina pseudomorphs fired at $900{ }^{\circ} \mathrm{C}$.

At $1000{ }^{\circ} \mathrm{C}$, only alpha and no kappa-alumina lines are detected, specially the characteristic $0.257 \mathrm{~nm}$ kappa-alumina reflection; however, their mixture is easily detected by SAED. The coexistence of kappa and alpha-alumina particles in mixture in the $1000{ }^{\circ} \mathrm{C}$ fired

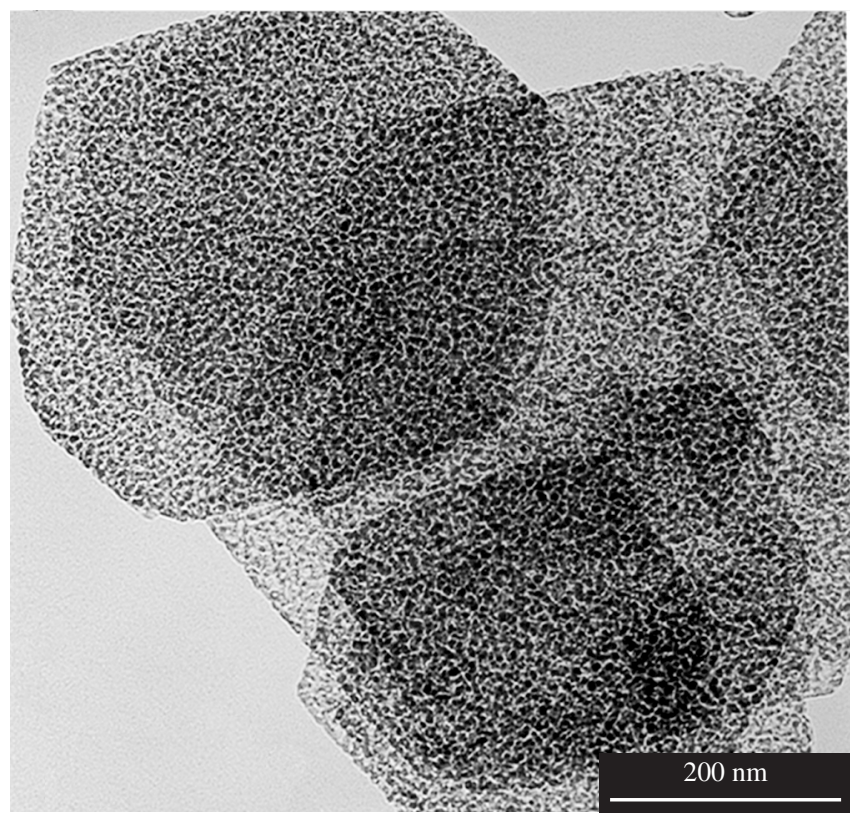

Figure 7. TEM of chi- $\mathrm{Al}_{2} \mathrm{O}_{3}$ from I-gibbsite platy crystals fired at $700{ }^{\circ} \mathrm{C}$ (LME-IF-USP).

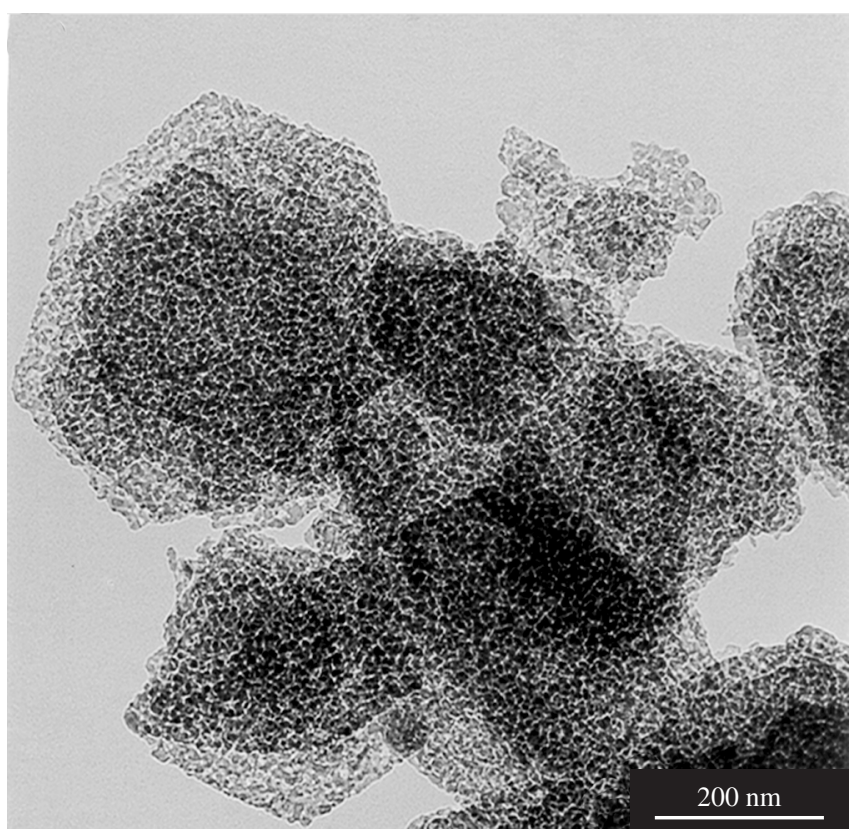

Figure 8. MET of kappa- $\mathrm{Al}_{2} \mathrm{O}_{3}$ from I-gibbsite platy crystals fired at $900{ }^{\circ} \mathrm{C}$ (LME-IF-USP). sample is clearly shown in transmission electron micrographs, as shown in Figure 9: a) the same pseudomorphs of Figure 9, constituted by small hexagonal platelets of kappa-alumina; b) electron dense lamellar crystals, many superposed, having smooth round irregular profiles, exhibiting Bragg contours and Moire fringes: they are sintered alpha-alumina crystals, as characterized by SAED. The kappa-alumina pseudomorphs are destroyed in the alpha-alumina crystallization. At $1100{ }^{\circ} \mathrm{C}$, only electronically coalesced round profile alpha-alumina crystals are observed.

Lippens and De Boer ${ }^{29}$ called attention to the work of De Boer et al. ${ }^{30}$ : "gibbsite crystals heated at lower temperature $\left(350{ }^{\circ} \mathrm{C}\right)$ formed slit-shaped pores which are separated by platelike particles paralled to each other and perpendicular to the c-axis of the original gibbsite crystal; at higher temperatures (not stated), however, rodlike particles are formed which are perpendicular to the c-axis of the original gibbsite crystal and parallel to each other. During sintering, even up to $1200{ }^{\circ} \mathrm{C}$, the rodlike structure of the $\mathrm{Al}_{2} \mathrm{O}_{3}$ is left undisturbed, in spite of the fact of the chi- $\mathrm{Al}_{2} \mathrm{O}_{3}$ is converted, via a number of intermediate stages, into alpha- $\mathrm{Al}_{2} \mathrm{O}_{3}$ ".

Wefers and Misra $^{18}$ (p. 56-59) presented TEM micrographs of chi, kappa and alpha-alumina from heated acicular gibbsite crystal: parallel the slit-shaped pores and platelike particles and perpendicular to the c-axis are observed, but no rodlike particle is mentioned from the micrographs.

In this paper, the original gibbsite crystals were observed perpendicular to the c-axis; so, the rodlike particles would appear inside the hexagon pseudomorph of chi-alumina and aligned radially. No rodlike particle was observed in the gibbsite crystals fired from 200 to $1100{ }^{\circ} \mathrm{C}$ : the chi and kappa-alumina microcrystals always appeared as hexagonal plates.

Up to $1500{ }^{\circ} \mathrm{C}$, the alpha-alumina crystals present sintering, pore formation, growth and recrystallization into round particles and plates, many with some $120^{\circ}$ angle; no hexagonal plate so as observed. Figure 10 is a TEM micrograph of alpha-alumina sample fired at $1500{ }^{\circ} \mathrm{C}$.

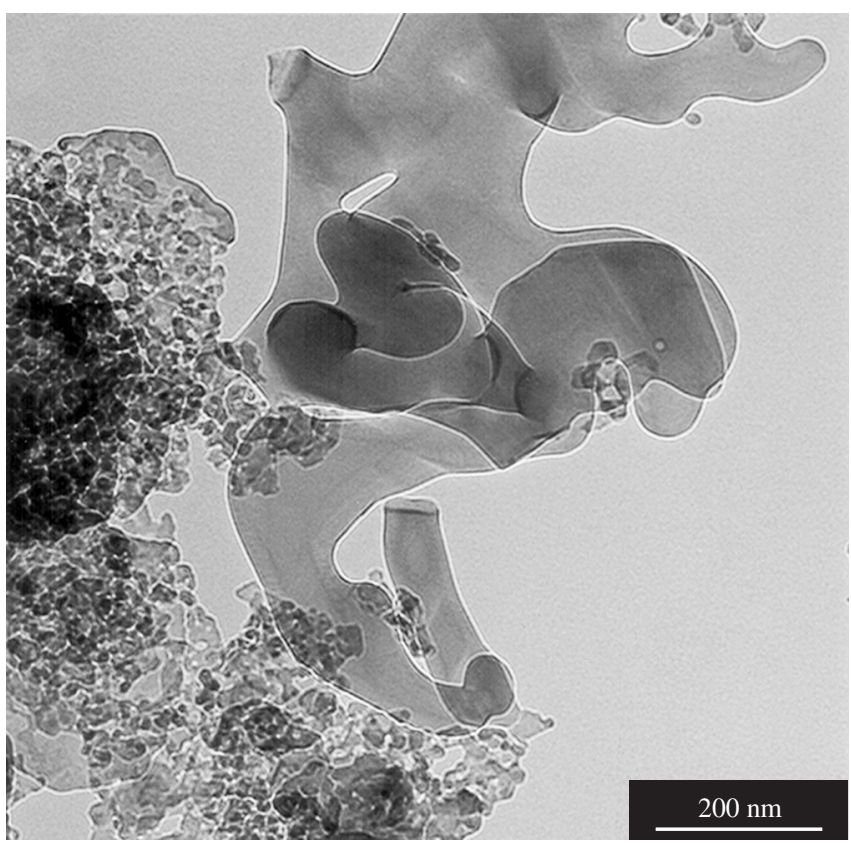

Figure 9. MET of kappa- $\mathrm{Al}_{2} \mathrm{O}_{3}+$ alpha- $\mathrm{Al}_{2} \mathrm{O}_{3}$ from I-gibbsite platy crystals fired at $1000^{\circ} \mathrm{C}$ (LME-IF-USP). 


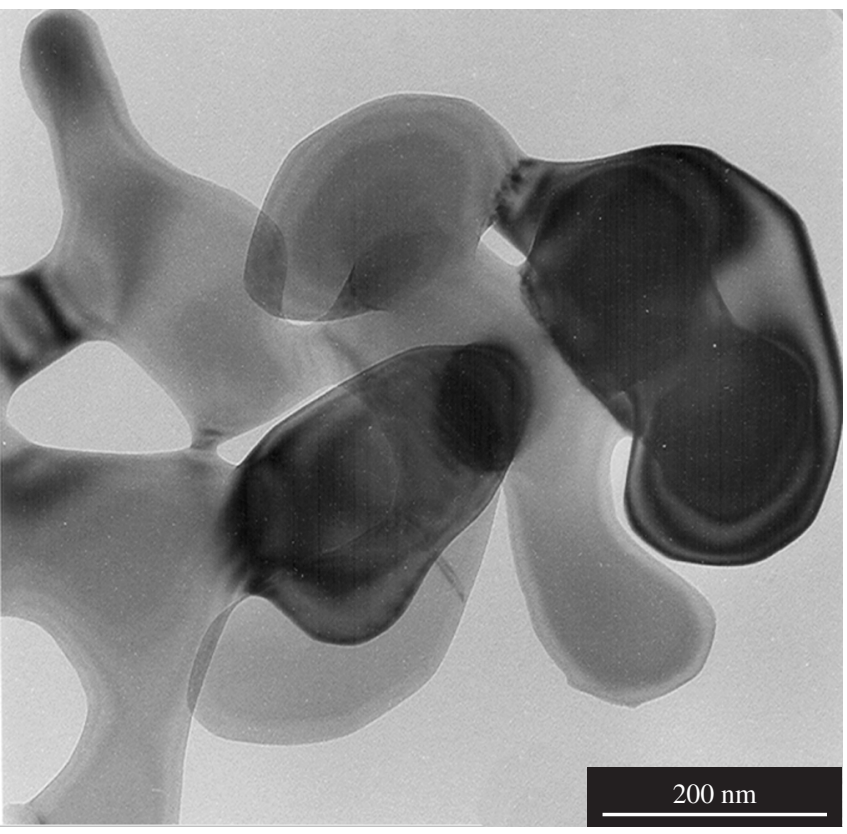

Figure 10. MET of alpha- $\mathrm{Al}_{2} \mathrm{O}_{3}$ from I-gibbsite platy crystals fired at $1500{ }^{\circ} \mathrm{C}$ (LME-IF-USP).

\section{Conclusions}

Gibbsite microcrystals, prepared by a new procedure using the reaction between aluminum powder and water, having iodine as activator, produce powders constituted by thin pseudohexagonal plates, 0.2 to $0.6 \mu \mathrm{m}$ in diameter, with specific surface areas of $24-25 \mathrm{~m}^{2} \cdot \mathrm{g}^{-1}$. The thermal transformation sequence of the I-gibbsite powder presents some differences from literature data on Bayer gibbsite; these differences are attributed to the small diameter and thinness of the I-gibbsite platy microcrystals. The I-gibbsite powder, fired between 200 and $1500{ }^{\circ} \mathrm{C}$, produces the chi-alumina series up to alpha-alumina (corundum). The maximum value of $347 \mathrm{~m}^{2} \cdot \mathrm{g}^{-1}$ of specific surface area, is obtained at $300{ }^{\circ} \mathrm{C}$; the powder has chialumina structure; $300{ }^{\circ} \mathrm{C}$ is the temperature of the endothermic dehydroxilation peak which indicates the end of the reaction I-gibbsite $\rightarrow$ chi-alumina + water (vapour). The new observed stability temperature ranges of the alumina phases are: a) I-gibbsite (up to $\left.200{ }^{\circ} \mathrm{C}\right)$; b) chi-alumina $\left(200\right.$ to $\left.900{ }^{\circ} \mathrm{C}\right)$; c) kappa-alumina (900 to $1000{ }^{\circ} \mathrm{C}$ ); d) kappa-alumina + alpha-alumina, (at $1000{ }^{\circ} \mathrm{C}$ ); and e) alpha-alumina (1000 to $\left.1500{ }^{\circ} \mathrm{C}\right)$. Therefore, it is possible with this gibbsite to obtain chi-alumina until $900{ }^{\circ} \mathrm{C}$, while with Bayer gibbsite the maximum temperature of stability is $673{ }^{\circ} \mathrm{C}$.

The selected area diffraction has shown more sensitivity than the XRD powder method for characterizing kappa-alumina, not detected by the later method at $1000{ }^{\circ} \mathrm{C}$ due to the very small particle size of the microcrystals.

\section{References}

1. Mackenzie RC, Meldau R. Die morphologie feinteilförmige oxid und hydroxide des eisens. aluminiums und mangan. Staub. 1967; 27(5):226-233.

2. Mackenzie RC, Follet EA, Meldau R. The oxides of iron, aluminium and manganese. In: Gard J, editor. Electron optical studies of clays. London: Mineralogical Society; 1975. p. 315-350.

3. McBride MB, Fraser AR, McHardy WJ. $\mathrm{Cu}^{2+}$ interaction with microcrystalline gibbsite: evidence for oriented chemisorbed copper ions. Clays and Clay Minerals. 1984; 32 (1):12-18.
4. Gastuche M C, Herbillon A. Etude des gels d'alumine: cristallization en millieu désionisé. Bulletin de la Société Chimique de France. 1962; 5:1404-1412.

5. Hsu PH. Aluminum hydroxides and oxyhydroxides. In: Dixon J B, Weed SB, editors. Minerals in Soil Environments, $2^{\text {nd }}$ ed. Soil Science Society of America, Madison, USA; 1989. p. 331-378.

6. Schoen R, Robeson C E. Structures of aluminum hydroxide and geochemical implication. American Mineralogist. 1970; 55(1-2):43-77.

7. MacZura G, Goodboy KP, Koenig JJ. Aluminum oxides. In: Kirk-Othmer's Encyclopedia of Chemical Technology, $3^{\text {rd }}$ ed. Wiley, New York. 1980; 1:p.221-243.

8. Misra C. Industrial alumina chemicals. American Chemical Society Monograph 184, Washington D.C. 1986. p. 46.

9. Hudson L K, Misra C, Wefers K. Aluminum oxides. In: Ulmann's Encyclopedia on Industrial Chemistry, $5^{\text {th }}$ ed. V C H-Verlaggesellschaft, Weinheim. 1985; A1: p. 588-629.

10. Sweegers C, Coninck HC, Meekes H, Enckevort WJP, Hiralal IDK, Rijkeboer A. Morphology, evolution and other characteristics of gibbsite crystals grown from pure and impure aqueous sodium aluminate solutions. Journal of Crystal Growth. 2001; 233(3):567-582.

11. Adamo P, Pigna M, Vingiani S, Violante A. A peculiar morphology of gibbsite and nordstrandite c-crystalized in the presence of atrate in a strongly alkaline environment. Clays and Clay Minerals. 2003; 51(3):350-353.

12. Tezaki K. Scanning electron microscopic study of formation of gibbsite from plagioclase. Papers of The Institute for Thermal Spring Research; Okayama: Okayama University. 1976. 45:11-24.

13. Souza Santos P, Campos T W, Souza Santos P, Kiyohara P K. Thermal phase sequences in gibbsite/kaolinite clay: electron microscopy studies. Ceramics International. 2005; 31(8):1077-1084.

14. Souza Santos H, Kiyohara PK, Vieira Coelho A C, Souza Santos P. Estudo por microscopia eletrônica das transformações durante a queima de argilas altamente aluminosas brasileiras. Cerâmica. 2006; 52(322):125-137.

15. Brown JF, Clark D, Elliott WW. The thermal decomposition of the alumina trihydrate gibbsite. Journal of The Chemical Society. (London). 1953 January; 84-88.

16. Brindley GW. Crystallographic aspects of some decomposition and recrystallization reactions. In: Mackenzie R C, editor. Progress in Ceramic Science vol.3. Pergamon Press, Oxford, UK; 1963. p.3-55.

17. Wefers K, Bell G M. Oxides and hydroxides of aluminum. Alcoa Technical Paper 12, Aluminum Company of America, Pennsylvania. 1972; p. $40-44$.

18. Wefers K, Misra C. Oxides and hydroxides of aluminum. Alcoa Technical Paper 19, Revised, Aluminum Company of America, Pennsylvania. 1987; p. $54-58$.

19. Wefers K. Nomenclature, preparation and properties of aluminum oxides, oxidehydroxides and trihydroxides. In: Hart L D, Lense E, editors. Alumina Chemicals. American Ceramic Society, Westerville, Ohio. 1990; p. 13-22.

20. Suzuki S. User die durch elektronenbestrahlung verursachte bberflächenzustandsänderung des hydrargillitkristalls. Kolloid Zeitung. 1953; 133(1):50-51.

21. Pandolfelli VC, Varela JA, Longo E. Alterações das características físicas, morfológicas e reológicas ocorridas na calcinação do hidróxido de alumínio. Cerâmica 1987; 33 (206):89-98.

22. Ginsberg H, Hüttig W, Stichl H. Uber die bildung von kristallinen $\mathrm{Al}(\mathrm{OH})_{3}$ und die umwandlung von bayerit in hydrargillit. Zeitschrift für anorganische und allgemeine Chemie. 1962(5-6); 318:238-256.

23. Antunes MLP, Souza Santos H, Souza Santos P. Characterization of the aluminum hydroxide microcrystals formed in some alcohol-water mixtures. Materials Chemistry and Physics. 2002; 76(3):243-249.

24. Souza Santos H, Kiyohara PK, Souza Santos P. A route for synthesis of microcrystalline gibssite in $\mathrm{Na}^{+}$free medium. Journal of Materials Science Letters. 2000; 19(17):1525-1527. 
25. Gitzen W H. Alumina as a ceramic material. American Ceramic Society, Columbus, Ohio. 1970. p. 12-22.

26. Oberlander P K. Aluminas for catalysts - Their preparation and properties. In: Leach B E, editor. Applied Industrial Catalysis vol.3. Academic Press, Orlando, USA. 1984. p. 63-112.

27. Levin I, Brandon D. Metastable alumina polymorphs: crystal structures and transition sequences. Journal of The American Ceramic Society. 1998; 81(8):1995-2012.
28. Souza Santos P, Souza Santos H, Toledo S P. Standard transition aluminas: Electron microscopy studies. Materials Research. 2000; 3(4):104-114.

29. Lippens BC, De Boear JH. Studies on pore systems in catalysis. V. The method. Journal of Catalysis. 1965; 4(3):319-323.

30. De Boer JH, Steggerda JJ, Zwietering P. The dehydration of alumina hydrates. III. Formation of the pore system during the dehydration of gibbsite. Proceedings of The Koninklijke Nederlandse Akademie van Wetenschappen. 1956; 859:435-444. 